\title{
Effectiveness of Anti-Graffiti Coatings used in Rolling Stock
}

\author{
GARBACZ Marcin ${ }^{1,} \mathrm{a}^{*}$ and KOWALIK Paweł ${ }^{1, b}$ \\ ${ }^{1}$ Instytut Kolejnictwa (The Railway Research Institute), Materials \& Structure Laboratory, 50, \\ Chlopicki Street, 04-275 Warsaw, Poland \\ *a mgarbacz@ikolej.pl, b pkowalik@ikolej.pl
}

\section{Keywords: Rolling Stock, Coatings, Graffiti Removal}

\begin{abstract}
The article presents the problem of graffiti on protective coatings on the wagon bodies of rail vehicles. It presents a way of dealing with this phenomenon by adding an anti-graffiti clear coat, allowing easy cleaning of graffiti without damaging the paint coat. The anti-graffiti clear coats available on the market and the agents used to wash them are briefly characterized. The research methodology and research results on the anti-graffiti protection effectiveness of various paint coats used in the railway industry, tested between the years 2010 and 2018 in the Railway Research Institute in the Materials \& Structure Laboratory, are also presented.
\end{abstract}

\section{Introduction}

Graffiti vandalism is a serious aesthetic and technical problem for owners and services responsible for the maintenance of rolling stock. Despite the fact that graffiti is not such a common problem as at the turn of the century, it still appears quite often on the rolling stock infrastructure, mainly causing material damage and large financial losses resulting from cleaning and, in the worst case, repainting. To effectively counteract unwanted graffiti painting, it is necessary to quickly remove the effects of the graffiti artists' work to discourage them from similar practices in the future, as they primarily care about their popularity, often signing their paintings with a pseudo-artistic nick and posting the effects of their work on the Internet. The best solution for this purpose is to protect the surface with a suitable quick and easy anti-graffiti remover. The currently applied paint coating types for new rolling stock have appropriate antigraffiti protection in the form of a clear coat, which additionally protects the coatings against harmful UV radiation and other external factors, while old rolling stock often cannot be cleaned, because graffiti is removed with the factory paint during its cleaning and the only solution to the problem is to re-paint the train. For many years now, Poland has been bound by the Normative Document DN 001/08/A2/2016 [1], which sets out the requirements for paint coatings intended for use in rolling stock. This document requires that such paint coatings have an anti-graffiti clear coat, which enables the easy removal of graffiti from a paint coating with appropriate protection.

\section{Railway anti-graffiti clear coats used in railway applications}

The most common anti-graffiti clear coats used in rolling stock to protect paint coats include polyurethane clear coats, which are classified as permanent systems without the need to renew the protective coating after washing (repeated washing possible) [2]. They are characterized by high resistance to washing agents used for cleaning rail vehicles and for graffiti removal. Such a clear coat is usually applied onto the base-coat or topcoat of the paint. When writing about an anti-graffiti clear coat, we refer to a product that allows undesirable subsequent paint coatings to be removed without damaging the original paint coat under reduced adhesion. Any substance present on the paint surface affects its structure, causing irreversible changes in the coating to a 
greater or lesser degree, until it is completely damaged and the non-resistant base-coat is exposed [3]. Other less common safety features used in rolling stock include so-called lost systems, which have a shorter protection time. The protection consists of applying a protective coating which separates the protected base-coat from paints. Once the coating is covered with graffiti, it is washed away with paints. Such coats usually consist of waxes, polyacrylates, microcrystalline waxes or paraffin emulsions. In this case, it is necessary to reapply the protective coating after the removal of graffiti (on the cleaned spot) as well as to apply the remover periodically on the surfaces subject to current maintenance, i.e. wagon bodies. The advantage of such systems is that there is no need to use any cleaning agents or removers (graffiti removal by means of a pressure washer with hot water), which generates lower graffiti removal costs $[2,5]$.

\section{Means and methods used to remove graffiti from railway infrastructure}

For the removal of unwanted graffiti in the railway industry, mechanical cleaning with hot water under pressure or special chemicals are applied, or both cleaning methods are combined. Various chemical agents are used to remove graffiti from paint coats, but they are usually in the form of liquids or gels. They contain organic substances, mainly aliphatic and aromatic hydrocarbons and tensides. The type of remover used should be adequate to the type of anti-graffiti protection applied and is usually determined by the manufacturer of a given paint or an entire painting system [3]. They are applied with a soft brush or sprayed on a large surface over graffiti and left for about 5 minutes, after which they are washed off by abrasion or stripping. Finally, the cleaned wagon is washed with soapy water and, at the end of the application, the wagons are rinsed with hot water. It should be noted here that, even though there is a satisfactory visual effect, invasive chemical graffiti removal methods affect the cleaned surface. Their repeated use may result in permanent damage. Chemical graffiti removal facilitates the repair and painting of the surface (in case the cleaning effect is not satisfactory). Painting over graffiti is very difficult and, in most cases, requires several coats of paint on it.

\section{Means used for graffiti painting}

The range of materials used by graphic artists is very wide, but the most common graffiti painting means used in the railway industry are spray paints and permanent markers. The main components of spray paints or graffiti markers are the following: pigment (a material that ensures color), binder (a film-forming transparent material in which pigment particles are dispersed and harden and bind the pigment on the painted surface) and a solvent that allows the flow of the pigment mixture/binder, where, in the case of markers, fast evaporating solvents are used to fix the writing instantly. Pigments can generally be divided into two groups:

- inorganic pigments, most of which occur in nature as minerals, such as titanium oxides TiO, $\mathrm{TiO}_{2}, \mathrm{ZnO}$ zinc oxide (white colors), lead chromate $\mathrm{PbCrO}_{4}$, zinc chromate $\mathrm{ZnCrO}_{4}$ (yellow colors), iron oxide $\mathrm{Fe}_{2} \mathrm{O}_{3}$ or lead oxide $\mathrm{Pb}_{3} \mathrm{O}_{4}$ (red colors). Blue and green pigments include ultramarine, Paris blue and chromium oxide (Cr2O3). The metallic colors in gold, silver and brown graffiti spray paints are obtained by adding aluminum, zinc, bronze, stainless steel or pearlescent pigments.

- organic pigments that are currently used to a much greater extent than their inorganic equivalents. Used in spray paints, they usually include substances, such as soot (the most common black pigment), phthalocyanine dyes, mainly blue and green, various azo compounds (e.g. toluidine red, lithium-bar red, yellow benzimidazolone) which cover about $70 \%$ of all organic pigments, carbonyl dyes as their salts and metal complexes $[4,6]$.

Binding agents are divided into natural (plant or animal) agents, agents prepared by chemical modifications of natural materials - semi-synthetic agents and synthetic polymers, which are the 
most commonly applied and will be briefly characterized. Synthetic agents (synthetic resins) can be divided into three main types: alkyd, acrylic and polyvinyl acetate $[4,6]$.

Alkyd agents (used as one of the first) are obtained by a reaction between polyalcohols and dicarboxylic acid. Most spray paints contain alkyd resins as binding agents. Such paints dry faster, are more durable and more difficult to remove than oil paints $[4,6]$.

Acrylic agents are obtained by polymerization of one or more monomers, which include mainly esters, acrylic acid and methacrylic acid. Acrylic polymer resins can be thermoplastic (the paint film is formed by evaporation of the solvent without chemical action) or thermosetting (the paint coat is hardened by heat or in reaction with another chemical substance to form a cross-linked structure) $[4,6]$.

Polyvinyl agents (PVA) are obtained by polymerization of vinyl acetate. PVA emulsions require the addition of plasticizers and emulsifiers, such as dibutyl phthalate or external plasticization by copolymerization $[4,6]$.

Other binders used in spray paints are polyurethanes, polyesters, cellulose, cellulose nitrate, epoxy resins, polycyclohexanone and chlorinated rubber (a mixture of natural styrene/butadiene rubber and chlorine). Paint containing chlorinated rubber is highly resistant to water and chemical products $[4,6]$.

Solvents used in the production of spray paints and markers can be divided into the following: hydrocarbon (aliphatic, naphthenic and aromatic), oxygen solvents (ketones, esters, glycol esters and alcohols) and water (components of the continuous phase of most emulsion paints), where hydrocarbon solvents are most commonly applied [4,6].

In addition to pigments, binders and solvents, paints also contain additives. Their amount is very small and no more than 5\%. These include plasticizers, dispersants (increasing the plasticity or fluidity of spray paints), surfactants, wetting agents (dispersing pigments), thickeners, $\mathrm{pH}$ buffers, and anti-foaming agents (changing the surface tension of paints) $[4,6]$.

\section{Research methodology:}

The anti-graffiti clear coat protection effectiveness was tested in the Laboratory of Materials \& Structure on appropriately prepared test panels of entire painting systems (with the same functional parameters of coatings used on wagon bodies). The tests were conducted on the basis of the ASTM D6578/D6578M-13 (2018) [7] standard, in accordance with the modified procedure. The modification of the standard included the adoption of an effectiveness assessment scale of anti-graffiti protection and the fact that only agents commonly used by graffiti artists, i.e. markers and sprays, were used for painting. The evaluation was performed using the A method, i.e. the assessment with corrected vision and the washing substances included specialist agents for removing graffiti based on organic solvents available on the market in the form of liquids, gels or tissues soaked in the appropriate substance.

The test procedure consisted of painting the coating on surfaces bounded by a suitable template on at least 3 samples evaluated against an extra, unpainted sample. The graffiti was left on the coating surface at room temperature for 24 hours and then it was removed by means of specified removers, where it was evaluated visually in natural daylight. The painting and washing process included 10 complete cycles. The test result is the specified efficiency of action of the anti-graffiti clear coat in the form of a number of cycles in relation to the point at which, after removal of a given graffiti painting on the coating surface, the change occurs for the first time (evaluation relative to gloss loss and color change). 

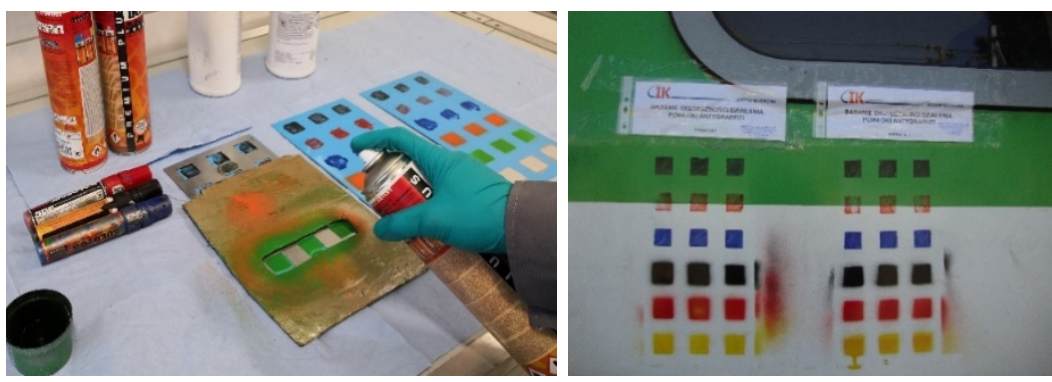

(b)

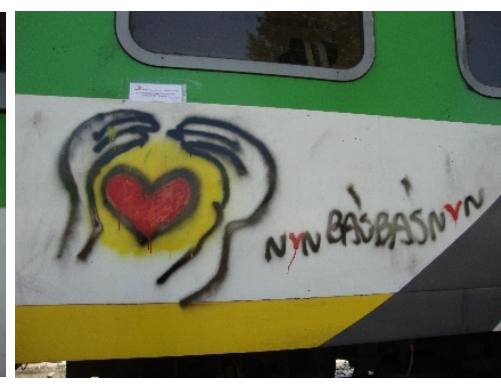

(c)

(a)

Figure 1. Example of graffiti made in a laboratory and on wagon bodies according to ASTM D6578/D6578M-13 ( $a$ and b), and example of graffiti found on rolling stock (c).

Table 1 summarizes the test results for several coating systems with anti-graffiti topcoats, which were painted and washed according to the procedure described above and which passed the remaining tests included in DN 001/08/A2/2016 [1]. The expanded measurement uncertainty $(\mathrm{P}=95 \%, \mathrm{k}-2)$ is \pm 2 painting cycles and has been determined from internal and external interlaboratory comparisons. Figure 1 shows the painting method in the laboratory and on wagon bodies according to ASTM D6578/D6578M-13 (2018) [7].

\section{Analysis of the results and conclusions:}

The above results show that the vast majority of the examined painting systems with the antigraffiti clear coat were characterized by a high protection effectiveness against painted graffiti. At least five coats of paint applied to the tested graffiti coatings and washed with graffiti removers recommended by the manufacturers of these coatings did not cause any visual changes, such as the loss of gloss or shadow formation and damage, such as blistering or peeling (they were imperceptible to the human eye). Thus, the majority of anti-graffiti clear coats currently available on the market meet the requirements for paint coats in rail vehicles contained in DN 001/08/A2/2016 [1]. According to this document, it is essential for the anti-graffiti clear coat to ensure that no changes are made to the paint coat surface after five cycles of application and washing of graffiti. In addition, in accordance with the document, painting systems should meet a number of other criteria, including high chemical and physical resistance, such as corrosion resistance, aging resistance and high resistance to chemicals due to frequent contact with cleaning agents on the railways.

The combined data in Table 1 also shows that there were differences in the ease of graffiti removal, expressed as the number of cycles without changes to the coating surface, depending on the type of material used to create the graffiti characters. It was harder to remove markers than spray paints. For Coat 14, three tested markers (Pentel black, blue and red) caused changes in the coating color after the first cycle, while for three tested spray paints, no changes were observed on the paint coat after performing 10 full cycles of painting and washing, which indicates that the coating reacts strongly with the applied markers. For Coats 2 and 12 (the same anti-graffiti clear coat, different marking agents) for markers of different manufacturers, completely different test results were obtained, whereas for applied spray paints of different manufacturers, no changes were observed after 10 cycles of painting and washing. The greatest difficulties in removing paint from Mołotow markers were observed for the red marker, which was the only alcoholbased marker. In the case of Pentel markers, the obtained results of resistance to painting are much weaker, but the manufacturer does not fully specify the composition of its markers, so it is not possible to determine the exact cause of the observed phenomenon. If the solvent is an alcohol, it can be a better transporting carrier for the dye and binder, which can penetrate deeper 
into the coating pores and bind more firmly to the coating than the acrylic markers used, for example. Differences in the results for markers and spray paints, in addition to composition, can also be explained by their different application methods. The markers are directly applied on the coating surface. The operator may exert different pressure on the coating, which may affect the ease with which the paint can be removed from the coating. This is not the case with spray paints as they are first thoroughly mixed by shaking the paint container and then sprayed onto the coating at a distance of approx. $25 \mathrm{~cm}$. It can therefore be assumed that the adhesion of spray paints is lower than that of markers. This makes it easier to remove spray paints without leaving any changes on the paint surface. In addition, the coating is chemically and mechanically damaged due to repeated contact between the writing tip and the coating in the case of markers, as well as due to washing with chemical agents as it loses its performance and protective properties, thus the thickness of the anti-gravity protection coating is also important.

During many years of research, it was also observed that the type of non-woven fabric used for removing anti-graffiti agents and graffiti influences the abrasion of the top anti-graffiti clear coat and consequently worsens its protective properties. The contact time of chemical cleaners should also be as short as possible and in accordance with the declarations of the manufacturers of dishwashing agents, as it also has a negative impact on the protective coating of paint, often causing irreversible changes in the coating (permanent discoloration or peeling of the coating).

It is extremely important to note that the paint systems tested, including the top graffiti coating, were not exposed to harmful weather conditions, so the actual effectiveness of coating protection in natural conditions may be much weaker, especially with the passage of time. The protection effectiveness will be reduced under the influence of external aging factors, such as light exposure to UV radiation, environmental conditions, such as changing weather conditions, air pollution or specialized chemical cleaning agents. Literature references show that the aging of samples significantly affects the results, which should also be taken into account when designing laboratory tests to check the quality of graffiti protection for a given paint / paint system $[2,5]$.

\section{Summary}

Based on the obtained data and many years of experience in laboratory research, it can be concluded that durable anti-graffiti clear coat systems seem to be one of the best possible solutions for the protection of railway wagons against vandalism. Anti-graffiti clear coat systems should be designed in symbiosis with the remover to investigate in detail the interaction between the coating, graffiti agent and solvent. This should be done to maintain the functional and decorative properties of the coating systems applied for as long and as efficiently as possible to reduce subsequent operating costs. 
Table 1. Comparison of the results of anti-graffiti paint resistance tests using various removers according to the methodology described in ASTM D6578/D6578M-13, performed in 2010-2018 in the Material \& Structure Laboratory.

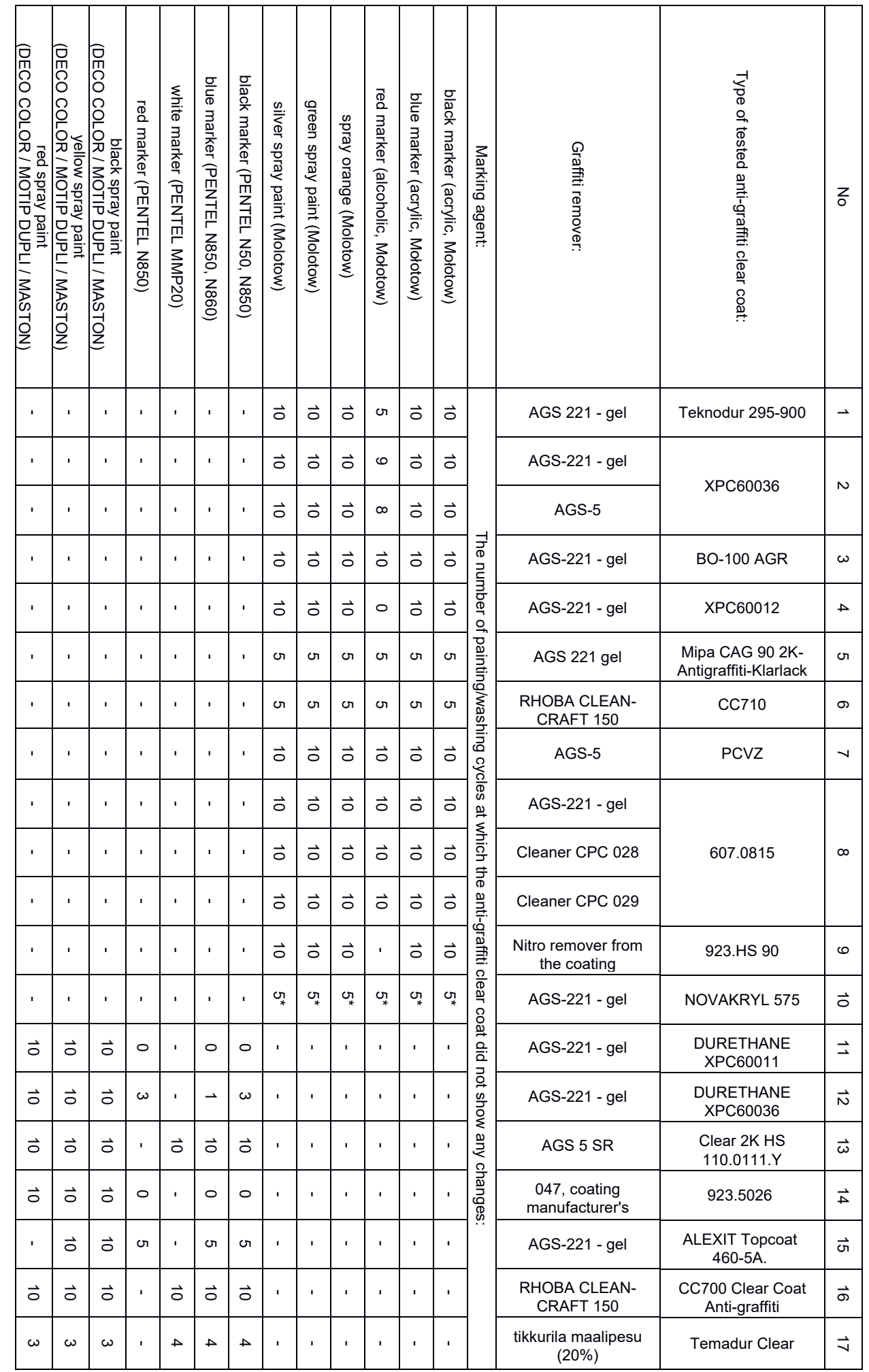

*Only a cycle of five paintings/washings has been carried out. 


\section{References}

[1] Normative Document DN 001/08/A2/2016 "Wyroby lakierowe stosowane w pasażerskim taborze szynowym - w lokomotywach, wagonach i zespołach trakcyjnych." (Painting products for passenger rolling stock - locomotives, wagons and train units)

[2] S. Rossi, M. Fedel, S. Petrolli, F. Deflorian, Characterization of the Anti-Graffiti Properties of Powder Organic Coatings Applied in Train Field, Coatings — Open Access Journal 2017, 7/67. https://doi.org/10.3390/coatings 7050067

[3] Ł. Pasieczyński, N. Radek, Problemy Kolejnictwa - Zeszyt 170 (marzec 2016) Badanie wybranych właściwości systemu powłokowego "antygraffiti” dla pojazdów szynowych (Examination of selected properties of anti-graffiti coating system for railway vehicles)

[4] R. Lambourne, T.A. Strivens. Paints and surface coatings. Theory and practice. Cambridge: Woodhead Publishing; 1999. https://doi.org/10.1533/9781855737006

[5] S. Rossi, M.Fedel, S.Petrolli, F.Deflorian, Behaviour of different removers on permanent anti-graffiti organic coatings, Journal of Building Engineering 5 (2016) 104-113. https://doi.org/10.1016/j.jobe.2015.12.004

[6] P. Sanmartín, F. Cappitelli, R. Mitchell, Current methods of graffiti removal: A review, Construction and Building Materials 71 (2014) 363-374.

https://doi.org/10.1016/j.conbuildmat.2014.08.093

[7] ASTM D6578/D6578M-13 (2018) Standard Practice for Determination of Graffiti Resistance 